\title{
Distribution and fine-scale spatial-genetic structure in British wild cherry (Prunus avium L.)
}

\author{
SP Vaughan ${ }^{1}$, JE Cottrell ${ }^{2}$, DJ Moodley ${ }^{1}$, T Connolly ${ }^{2}$ and K Russell ${ }^{1}$ \\ ${ }^{1}$ East Malling Research, New Road, East Malling, Kent, UK and ${ }^{2}$ Forest Research, Northern Research Station, Roslin, Midlothian, UK
}

Insights into the within-population spatial-genetic structure (SGS) of forest tree species, where little is known regarding seed and pollen dispersal patterns, enhance understanding of their ecology and provide information of value in conservation and breeding. This study utilised 13 polymorphic simple sequence repeat loci to investigate the impact of asexual recruitment, management regime and tree size on the development of SGS in wild cherry (Prunus avium L). Only 246 genotypes were identified in the 551 trees sampled, reflecting significant levels of clonal reproduction in both managed and unmanaged populations. Naturally regenerated wild cherry was spatially aggregated under both management regimes. However, in the managed population, sexually derived trees accounted for a greater proportion of the smaller size classes, whereas vegetatively produced trees dominated the smaller size classes in the unmanaged population. High overall SGS values (Sp 0.030-

Keywords: clonality; Prunus; sexual reproduction; SGS; SSR
Sp 0.045) were observed when considering only sexually derived genets and kinship coefficients were significant up to the $120 \mathrm{~m}$ distance class for both populations. The inclusion of clonal ramets in the analysis significantly increased the overall SGS ( $S p 0.089-S p$ 0.119) as well as kinship coefficients in the 40-80 m distance classes, illustrating the dramatic impact of vegetative propagation on SGS in this species. Increased spatial aggregation and regeneration appeared to be concomitant with increased SGS in the $40 \mathrm{~m}$ distance class in the unmanaged population. Neighbourhood size estimates were relatively small for both populations and kinship coefficients were found to decline with distance under both management regimes, suggesting that common mechanisms may restrict gene dispersal in wild cherry.

Heredity (2007) 98, 274-283. doi:10.1038/sj.hdy.6800935; published online 24 January 2007

\section{Introduction}

Non-random distribution of genotypes in plant populations gives rise to the development of spatial-genetic structure (SGS) at a variety of scales (Silvertown, 2001; Vekemans and Hardy, 2004). Population history, vicariance, species ecology and management regime may all influence the degree to which SGS develops in a population (Chung and Epperson, 2000; Marquardt and Epperson, 2004). In plant populations, the occurrence and magnitude of SGS is strongly influenced by life form, mating system and population density (Vekemans and Hardy, 2004; Ward et al., 2005). In a study comparing SGS in 47 plant species, genetic structuration was typically stronger in insect pollinated species, where seed is dispersed by gravity and frugivores than in species pollinated and dispersed by wind (Vekemans and Hardy, 2004). Gaining awareness of within-population SGS in forest tree species, where little is known regarding seed and pollen dispersal patterns, is vital to further the understanding of the ecology of the species and also to inform conservation and breeding strategies (Streiff et al., 1998; Cottrell et al., 2003).

Correspondence: Current address. Dr SP Vaughan, Rothamsted Research, Harpenden, AL5 2JQ Herts, UK

E-mail: sp_vaughan@yahoo.com

Received 7 June 2006; revised 16 September 2006; accepted 26

November 2006; published online 24 January 2007
This study concerns wild cherry (Prunus avium L.), which is a diploid member of the Rosaceae that occurs naturally from western Eurasia to northern Africa. Wild cherry is an economically important noble hardwood species with valuable timber and is a frequent component of woodland margins throughout Europe (Russell, 2003). Reproduction in wild cherry occurs asexually via suckering and sexually through insect-mediated pollination and subsequent seed dispersal by birds and mammals. Despite its abundance and the high value of its timber, few studies have examined reproductive processes in natural stands of wild cherry and little is understood regarding either seed or pollen dispersal. By assessing SGS, it is possible to gain further understanding of family groupings and patterns of effective gene flow in wild cherry. Inferences drawn from SGS data may therefore inform strategies to promote selection of genetically diverse material for seed orchards to maintain the adaptive and economic potential of future plantings.

Earlier studies of French wild cherry, employing isoenzyme markers, revealed no significant levels of SGS (Frascaria et al., 1993). However, in a Slovakian wild cherry population, isoenzyme polymorphism did reveal significant levels of SGS in the first distance class examined $(<36.8 \mathrm{~m})$ (Gömöry and Paule, 2001). Microsatellite or simple sequence repeat (SSR) markers are codominant and highly polymorphic and have been widely used in forest tree population studies over recent 
years (Godoy and Jordano, 2001; Asuka et al., 2004; Heuertz et al., 2004; Marquardt and Epperson, 2004). Recently, we have optimized a suite of SSR markers from $P$. avium to enable the efficient genotyping of wild cherry in population scale studies (Vaughan and Russell, 2004).

Using SSR markers, we aimed to: (1) describe the genetic diversity present in two populations of British wild cherry; (2) examine patterns of SGS in wild cherry under contrasting management regimes; (3) evaluate the impact of asexual reproduction and variation between size classes of individuals on SGS. We expected that significant SGS would be present owing to the restricted spatial distribution of clonal genotypes. Furthermore, we anticipated that if seed and pollen dispersal are limited in this species, then we would observe significant levels of SGS in the smaller distance classes when considering only sexually produced genets. In terms of management regime, we expected SGS to be weaker in the managed population where, although regenerating naturally, the natural succession may be disturbed by removal of a proportion of the mature cohort for timber.

\section{Materials and methods}

\section{Study area}

The study area is situated at Fawkham Green, Kent, UK (51:21:39N, 0:16:34E) and comprises two adjacent ancient woodlands, where woodland cover has been continuous since at least $1600 \mathrm{AD}$, and where trees have arisen through natural regeneration or coppice regrowth. Population A (Saxtens and Cages Wood, 19Ha) is a good example of ancient semi-natural woodland with a diverse species profile and abundant natural regeneration of many tree species. The herb layer is characterized by many ancient woodland indicator species and the woodland floor is relatively open throughout. This site is owned and managed (removal of poor quality trees, clearing of understorey and thinning of dense areas of regeneration) by the Woodland Trust. Population B (Rogers Wood, 10 Ha) lies adjacent and immediately to the south of population $\mathrm{A}$ and has been unmanaged for a minimum of 20 years. Although bramble (Rubus spp) dominates the herb layer in this woodland, ancient woodland indicator species persist in places. However, natural regeneration of most tree species is scarce. Significant storm damage in both 1987 and 1990 has resulted in many fallen trees, most of which remain in situ. Further small woodlands, separated from the study area by pastureland, containing mature wild cherry lie approximately $800 \mathrm{~m}$ to the north and $1 \mathrm{~km}$ to the south. A $5 \mathrm{Ha}$ immature woodland planting also containing wild cherry lies immediately adjacent to the East of Population A.

\section{Geographic, physiological and phenological measurements}

All wild cherry, over 3 years old, were identified in the study area through multiple surveys, including an aerial survey during the flowering season, over a period of several months. The geographical position of all trees was mapped using a directional compass and a laser distance measurer (Leica Disto Lite 5) accurate to $0.5 \mathrm{~cm}$ over $100 \mathrm{~m}$ (Leica Geosystems, Heerbrugg, Switzerland). The diameter at breast height $(\mathrm{DBH})$ of each tree was also measured using a tape measure. The physical distribution of wild cherry was quantified by calculating the aggregation index $(R)$ (Clark and Evans, 1954) for each population using the SGS software (Degen et al., 2001). $R$ values of less than 1 indicate a clumped and aggregated distribution of individuals. $R$ values of 1 indicate a random distribution and values in excess of 1 indicate a more regular distribution of individuals within the study site.

Several clonal groups were identified containing multiple ramets of identical genotype. For each clonal group, average values were calculated for phenological measurements and spatial coordinates approximated for the mid-point of the clonal group. These values were used to represent a hypothetical sexually generated progenitor for each clonal group. To establish if SGS was likely to be influenced by temporal differences in pollen availability between 'family' groups, the dates of floral bud break and progression towards full bloom were recorded for each tree between 26 March 2003 and 7 May 2003. Each tree was visually examined so that the week in which flowering started could be determined. After flowering commenced, the proportion of flowers open on each tree was estimated on a weekly basis. Stages were characterized as $<10 \%$ open, $11-50 \%$ open, $51-75 \%$ open, $76-99 \%$ open and $100 \%$ open.

\section{DNA extraction and SSR analysis}

Genomic DNA was extracted from two dormant buds collected from each tree as described previously (Vaughan and Russell, 2004). Fluorescent primers, optimized to characterize variation at 13 SSR loci, were used to determine the genotype of each wild cherry within the study site using three multiplex polymerase chain reaction (PCR) reactions. Multiplexes A and $B$ were as described in Vaughan and Russell (2004). A third multiplex was also developed incorporating the primers for SSR loci UDP98-412 from peach (Cipriani et al., 1999) and PceGA34 from sour cherry (Downey and Iezzoni, 2000). PCR reactions and analysis of PCR amplification products were carried out exactly as described in Vaughan and Russell (2004). A minimum of six control samples were included in each 96-well plate to ensure reproducibility of allele scores between plates. Allele scores were evaluated by two researchers independently and any samples generating unexpected profiles or weak electrophorograms were repeated to verify the data.

\section{Statistical analysis}

Analyses initially included all ramets. However, when assessing the sexually produced component of the population only one representative per clonal group, with spatial coordinates approximated to the mid-point of the group, was included. A more detailed analysis of clonal structure and recruitment in wild cherry will be presented in a separate paper. Allele frequencies and conformation to Hardy-Weinberg equilibrium, according to Nei (1987), were determined using the CERVUS software (Marshall et al., 1998). The informativeness of each locus was calculated both in terms of expected heterozygosity $\left(H_{\mathrm{E}}\right)$ and observed heterozygosity $\left(H_{\mathrm{O}}\right)$ (Nei, 1987). Allelic richness ( $\hat{A})$, a measure of the number of alleles independent of sample size, was calculated using a rarefaction index in the FSTAT program (Goudet, 
1995). Probabilities assigned to a Wilcoxon signed-rank test (Siegel, 1956) were used to check for significant differences between diversity parameters in the two populations examined. Fisher's exact test, computed in GENEPOP, was used to calculate differences between the allele and genotype frequencies of the two populations. The differentiation statistic $F_{\mathrm{ST}}$ was calculated using the Arlequin software program (Schneider et al., 1997) for diploid data based on the method of (Weir and Cockerham, 1984) and standardized $F_{\mathrm{ST}}\left(G_{\mathrm{ST}}^{\prime}\right)$ calculated according to Hedrick (2005).

SGS was estimated using the software SPAGEDI (Hardy and Vekemans, 2002). A multilocus kinshipbased approach was adopted using the $F_{i j}$ statistic (Loiselle et al., 1995), following the approach adopted by Hardy et al. (2006), this measures the genetic similarity between individuals $i$ and $j$ relative to the mean genetic similarity between random individuals in the sample. Reference allele frequencies were derived separately for each population and incorporated one ramet per genotype except in the instances where the effect of asexual reproduction on SGS was being estimated. A distance class of $40 \mathrm{~m}$ was chosen for all analysis as this allowed for direct comparison between the different parameters being assessed, while providing a reasonable distribution of samples across distance and allowing regression of kinship against log distance over reasonable distances for both populations. The intensity of SGS was estimated in terms of the $S p$ statistic (Vekemans and Hardy, 2004), again using the software SPAGEDI, whereby kinship coefficients were calculated for each locus and all loci combined within each population. Neighbourhood size $\left(N_{\mathrm{b}}\right)$ was estimated using the iterative procedure described by Hardy et al. (2006) until $N_{\mathrm{b}}$ estimates converged. Gene dispersal distances $\left(\sigma_{\mathrm{g}}\right)$ were also estimated according to the procedure described by Hardy et al. (2006) and tested at four $(D / 2, D / 4.5, D / 5$ and $D / 10)$ assumed effective densities $\left(D_{\mathrm{e}}\right)$ relative to the observed density $(D)$. D/4.5 was included as an effective density as this was the lowest level at which the estimation procedure could reach convergence for population B and thus, enable comparison of gene dispersal distances at two effective densities for both populations.

\section{Results}

\section{Distribution of wild cherry and the impact of asexual reproduction}

A total of 551 wild cherries were sampled from the two populations. However, a significant proportion of these were found to represent ramets of the same genet. A total of 246 genotypes were detected: 163 genotypes for 314 trees sampled in population A (managed) and 83 genotypes for 237 trees sampled in population B (unmanaged). Thus, asexual reproduction accounted for approximately $48-65 \%$ of recruitment in populations A and $B$, respectively. This greatly affects the distribution of cherry in the two populations. Aggregation $(R)$ indices for sexually derived individuals were 0.557 and 0.453 for populations $\mathrm{A}$ and $\mathrm{B}$, indicating a clustered distribution. When also considering asexually derived ramets, $R$ values of 0.416 and 0.286 were observed for populations $A$ and $B$, respectively. This indicates that the physical distribution of wild cherry is appreciably more clustered in the unmanaged population, and that clonal reproduction significantly influences spatial distribution in both populations.

\section{$\mathrm{DBH}$ distribution of wild cherry}

The DBH range observed was similar in both populations. However, it was noted that on average, $\mathrm{DBH}$ in the managed population was significantly $(P<0.05)$ higher than that observed in the unmanaged population. Closer examination of the distribution of $\mathrm{DBH}$ within the two populations revealed that significant proportions of both genets and ramets in both populations were made up of small $(<9.55 \mathrm{~cm}) \mathrm{DBH}$ trees (Figure 1). It was also noted that the proportion of individuals per size class declined as DBH increased (Figure 1), suggesting that significant mortality occurs throughout the population as trees mature. Examination of the proportion of individuals in each DBH size class having arisen through sexual reproduction, or via suckering, revealed contrasting trends between the two populations. In the managed population, sexually derived genets account for a greater proportion of the two smaller DBH classes and a lesser proportion of the higher DBH size classes (Figure 1). In contrast, in the unmanaged population, this trend is reversed and vegetatively produced ramets dominate all DBH size classes except the very highest (Figure 1).

Floral phenology was investigated to determine if SGS was reinforced by temporal differences in availability of pollen between different genotypic groups. However, in the year of study, $96 \%$ of the trees were at 76-99\% full bloom by 30 April and all flowers had opened by 7 May. Thus, flowering in all the trees in the study site overlapped to some degree, and it was theoretically possible for every tree to contribute to the pollen cloud when some flowers on every tree were receptive. However, further analysis revealed a link between the progression towards full bloom and tree size. Trees of below $9.55 \mathrm{DBH}$ ( $30 \mathrm{~cm}$ circumference) commenced flowering considerably earlier than trees in the larger size cohorts and the majority of trees in this cohort had attained over $50 \%$ full bloom a week ahead of the majority of trees in the older cohorts (Figure 2).

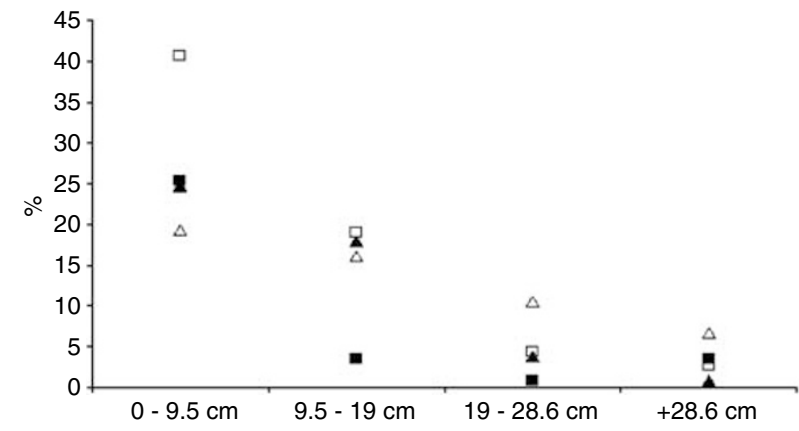

Figure 1 Percentage of wild cherry in different DBH size classes. Triangles indicate values for the managed population (A). Solid triangles indicate values for sexually derived genets, open triangles indicate values for asexually derived ramets. Squares indicate values for the unmanaged population (B). Solid squares indicate values for sexually derived genets, open squares indicate values for asexually derived ramets. 

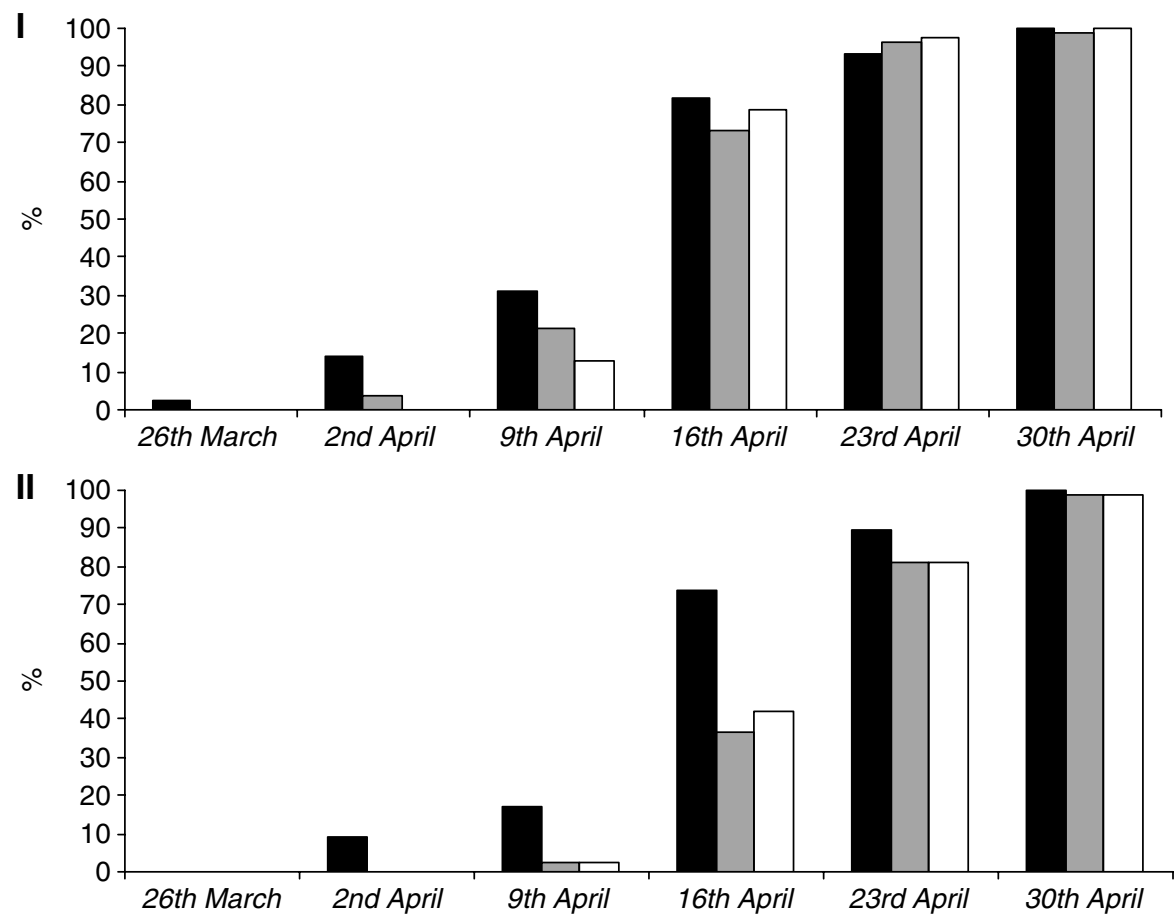

Figure 2 Floral phenology in wild cherry of different size cohorts in ancient woodland. The percentage of trees with any flowers open (I) and with over $50 \%$ of flowers open (II) at the dates indicated in 2003 are presented for three size cohorts: smallest trees $(<9.55 \mathrm{~cm} \mathrm{DBH})$, black bar; middle-sized trees $(9.55-19 \mathrm{~cm} \mathrm{DBH})$, hatched bar; largest trees $(19-59 \mathrm{~cm} \mathrm{DBH})$, white bar.

Table 1 SSR locus diversity measures for sexually derived genotypes of wild cherry in two populations: A (managed) and B (unmanaged)

\begin{tabular}{|c|c|c|c|c|c|c|c|c|c|c|c|c|}
\hline \multirow[t]{2}{*}{ Locus } & \multicolumn{2}{|c|}{$\mathrm{n}$} & \multicolumn{2}{|c|}{$\hat{A}$} & \multicolumn{2}{|c|}{$\mathrm{H}_{O}$} & \multicolumn{2}{|c|}{$\mathrm{H}_{E}$} & \multicolumn{2}{|c|}{$H W$} & \multicolumn{2}{|c|}{$\mathrm{P}$} \\
\hline & $A$ & $B$ & $A$ & B & $A$ & B & $A$ & B & $A$ & $B$ & Allele & Genotype \\
\hline EMPaS01 & 5 & 4 & 4.77 & 4 & 0.650 & 0.699 & 0.634 & 0.626 & NS & NS & $<0.000$ & $<0.000$ \\
\hline EMPaS02 & 8 & 8 & 7.03 & 8 & 0.810 & 0.855 & 0.737 & 0.751 & NS & $* *$ & 0.043 & NS \\
\hline EMPa004 & 9 & 7 & 6.95 & 7 & 0.595 & 0.627 & 0.611 & 0.586 & NS & NS & $<0.000$ & $<0.000$ \\
\hline EMPa005 & 7 & 7 & 6.28 & 7 & 0.736 & 0.735 & 0.728 & 0.746 & NS & NS & NS & NS \\
\hline EMPaS06 & 9 & 6 & 7.77 & 6 & 0.890 & 0.892 & 0.783 & 0.781 & NS & NS & 0.018 & 0.007 \\
\hline EMPaS10 & 9 & 8 & 7.63 & 8 & 0.706 & 0.747 & 0.653 & 0.706 & NS & NS & $<0.000$ & $<0.000$ \\
\hline EMPaS11 & 9 & 7 & 7.80 & 7 & 0.577 & 0.614 & 0.535 & 0.560 & NS & NS & $<0.000$ & $<0.000$ \\
\hline EMPaS12 & 7 & 8 & 5.50 & 8 & 0.736 & 0.711 & 0.705 & 0.663 & NS & NS & $<0.000$ & $<0.000$ \\
\hline EMPaS14 & 5 & 6 & 4.03 & 6 & 0.626 & 0.578 & 0.593 & 0.595 & NS & NS & NS & NS \\
\hline EMPa015 & 13 & 11 & 10.89 & 11 & 0.687 & 0.566 & 0.650 & 0.592 & NS & NS & NS & 0.013 \\
\hline EMPa018 & 10 & 8 & 8.31 & 8 & 0.693 & 0.711 & 0.679 & 0.703 & NS & NS & $<0.000$ & $<0.000$ \\
\hline PceGA34 & 14 & 14 & 11.71 & 14 & 0.810 & 0.831 & 0.765 & 0.853 & NS & NA & NS & NS \\
\hline UDP98-412 & 9 & 7 & 7.78 & 7 & 0.798 & 0.711 & 0.758 & 0.755 & $* *$ & NS & $<0.000$ & $<0.000$ \\
\hline Average & 8.77 & 7.77 & 7.42 & 7.77 & 0.716 & 0.714 & 0.679 & 0.686 & $N A$ & $N A$ & $N A$ & $N A$ \\
\hline$P$-WSR & \multicolumn{2}{|c|}{0.031} & \multicolumn{2}{|c|}{ NS } & \multicolumn{2}{|c|}{ NS } & \multicolumn{2}{|c|}{ NS } & \multicolumn{2}{|c|}{ NA } & NA & NA \\
\hline
\end{tabular}

Abbreviations: $n=$ actual number of alleles observed; $\hat{\mathrm{A}}=$ allelic richness (corrected in population A to account for smaller sample set in population B); $H_{\mathrm{O}}=$ observed heterozygosity; $H_{\mathrm{E}}=$ expected heterozygosity; $\mathrm{HW}=$ Hardy-Weinberg equilibrium; NS=non-significant deviation; NA = test not applied.

**Represents significant deviation from HW at the $1 \%$ level. Average values (italicised) are given for each category where applicable. $P$-WSR = the probability that measures of genetic diversity are significantly different between the two populations (calculated using Wilcoxon signed rank tests). Differences between the allele and genotype frequencies of the two populations were calculated using exact Fisher's tests and the $P$-values given (NS: $P>0.05$ ).

\section{Measures of diversity}

A total of 116 alleles were observed and moderately high levels of polymorphism were exhibited by almost all the SSR loci examined (Supplementary information available at Heredity's website). Allelic richness (Â) was comparable between the two populations: 7.50 in population A and 7.85 in population B (Table 1). Of the 116 alleles observed, 11 were found to be exclusive to population $\mathrm{A}$ and nine were exclusive to population B. All exclusive alleles were identified at very low frequencies (average 0.002), were present in no more than two individuals and always in a heterozygous state. However, significant differences between the two populations were observed both for allele and genotype frequencies at several of the loci examined (Table 1). 
Al

One ramet / genet included
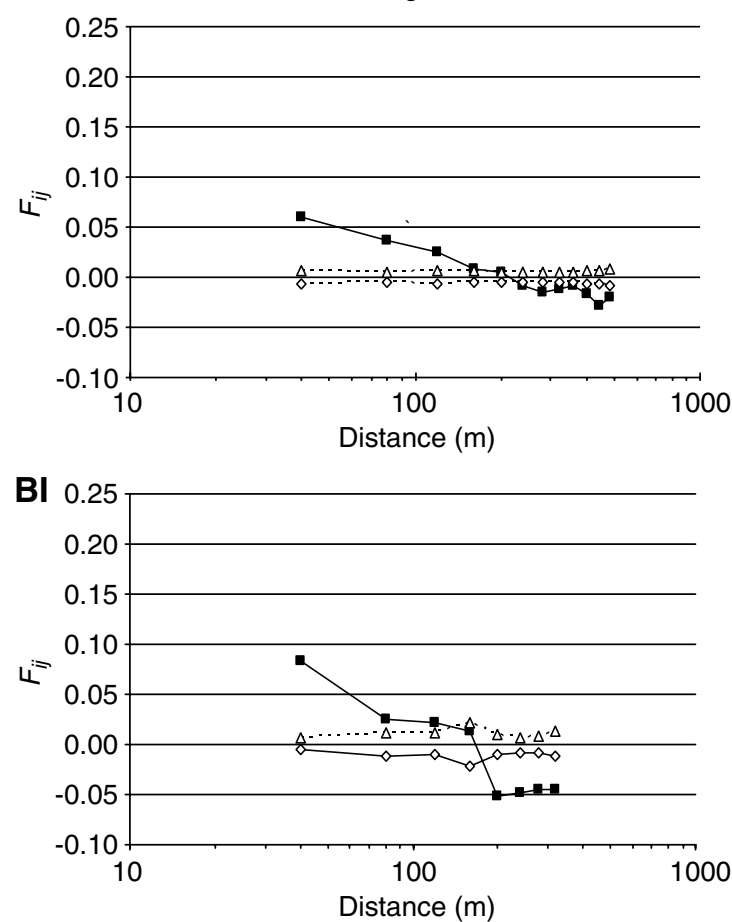

All

All ramets included

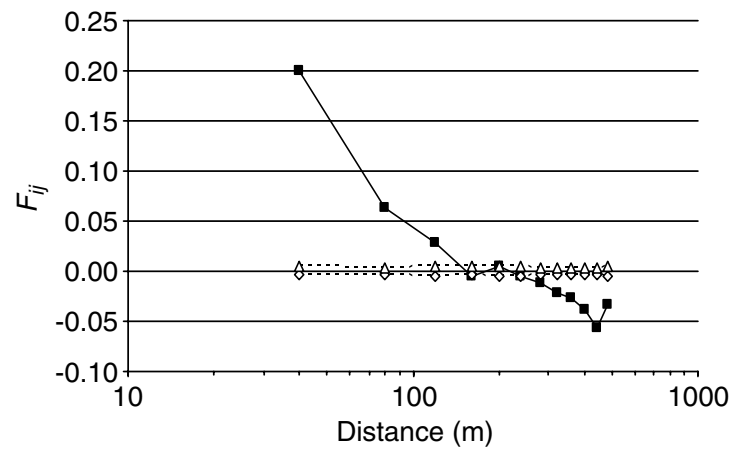

BII

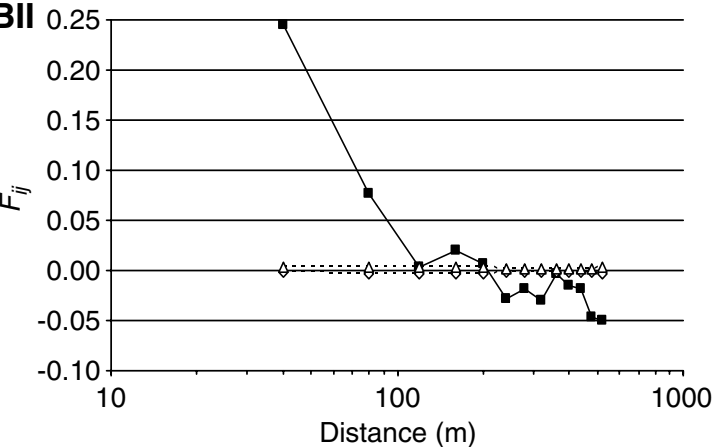

Figure 3 Comparison of SGS in managed (A) and unmanaged (B) populations of wild cherry. Kinship coefficient $\left(F_{i j}\right)$ values are presented for one ramet per clonal group (AI and BI) and for all ramets (AII and BII) for each population. $F_{i j}$ values are indicated with a solid line and black square for each $40 \mathrm{~m}$ distance class on a logarithmic scale. Upper and lower $95 \%$ confidence limits for each distance class are indicated by a dotted line with an open triangle and diamond, respectively.

The relative informativeness of each SSR locus was evaluated using several measures of polymorphism and heterozygosity (Table 1) and no significant differences were observed between the unmanaged and managed populations in terms of among population diversity measures. Mean $H_{\mathrm{O}}$ levels were highly similar between the two populations: 0.717 and 0.723 for populations $A$ and $\mathrm{B}$, respectively. Mean $H_{\mathrm{E}}$ levels were also highly similar: 0.663 and 0.667 for populations $A$ and B, respectively. When considering only genets derived from sexual reproduction, deviation from HardyWeinberg equilibrium was observed for only one of the 13 loci examined in each of the two populations (UDP98412 in population $\mathrm{A}$ and $\mathrm{EMPaSO2}$ in population B). Furthermore, in terms of population $F_{\mathrm{ST}}$, relatively little genetic differentiation $\left(F_{\mathrm{ST}} 0.022\right)$ was observed between the two populations. Increased differentiation $\left(G_{S T}^{\prime} 0.07\right)$ was observed when assessing the data using the newly proposed standardized measure, $G^{\prime}{ }_{\mathrm{ST}}$, which allows for comparison of loci displaying different levels of genetic variation.

\section{Impact of management regime and clonality on SGS}

The impact of asexual reproduction on SGS in wild cherry was expected to be great, as the physical linkage of identical genotypes will obviously result in nonrandom distribution of genotypes. SGS was characterized by subdividing each population into $40 \mathrm{~m}$ distance classes and plotting average kinship coefficient $\left(F_{i j}\right)$ relationships, over all 13 loci, against the logarithm of the distance. Clonality significantly influenced the strength of kinship coefficients in the first distance class in both populations with $F_{i j}$ values approximately three times higher when considering all ramets as opposed to a single ramet per genotype (Figure 3). Management regime appeared to have a less significant effect on SGS patterns. Kinship coefficients were slightly lower in the managed population, but a constant decline in $F_{i j}$ values with distance was observed for both populations (Figure 3). Significant SGS was observed in distance classes up to $120 \mathrm{~m}$ in both populations when considering only one ramet per genet (Figure 3). The large $F_{i j}$ value observed in the first $(40 \mathrm{~m})$ distance class may be linked to the high level of spatial aggregation observed in this population. However, the constant decline in SGS with distance suggests that common dispersal processes may influence genotype distribution irrespective of management regime and that seed dispersal is somewhat limited in this species.

The overall intensity of SGS present in each population was also quantified using the $S p$ statistic (Vekemans and Hardy, 2004). When considering both sexually derived genets and all vegetatively produced ramets significant, strong SGS was observed, $S p=0.089$ and $S p=0.119$ in the managed and unmanaged populations, respectively. The higher values in the unmanaged population likely reflect increased levels of asexual recruitment (Figure 1). Furthermore, the slope of the relationship between kinship and log distance is not linear and decreases sharply between the first and second distance classes, indicating the significant, yet spatially restricted, effect that clonality has upon SGS in this species. When considering only one ramet per genet, the $S p$ values were 
Table 2 Estimates of SGS parameters for wild cherry in managed (A) and unmanaged (B) populations showing the effect of clonality (I) and tree size (II)

\begin{tabular}{|c|c|c|c|c|c|c|}
\hline & Population & Category & (m) & $\mathrm{F}_{1}$ & b (s.e.) & $\mathrm{Sp}$ \\
\hline \multirow[t]{4}{*}{ I } & A & One ramet/genotype & $0-480$ & 0.061 & $-0.028(0.004)$ & 0.030 \\
\hline & A & All ramets & $0-480$ & 0.199 & $-0.070(0.007)$ & 0.089 \\
\hline & B & One ramet/genotype & $0-320$ & 0.083 & $-0.041(0.006)$ & 0.045 \\
\hline & B & All ramets & $0-320$ & 0.198 & $-0.096(0.013)$ & 0.119 \\
\hline \multirow[t]{5}{*}{ II } & $\mathrm{A}$ & $\mathrm{DBH}<9.55 \mathrm{~cm}$ & $0-360$ & 0.079 & $-0.035(0.008)$ & 0.038 \\
\hline & A & DBH $9.55-19 \mathrm{~cm}$ & $0-400$ & 0.042 & $-0.022(0.003)$ & 0.022 \\
\hline & A & DBH $19-59 \mathrm{~cm}$ & $0-400$ & 0.112 & $-0.036(0.005)$ & 0.041 \\
\hline & B & $\mathrm{DBH}<9.55 \mathrm{~cm}$ & $0-280$ & 0.075 & $-0.039(0.010)$ & 0.042 \\
\hline & B & DBH $9.55-59 \mathrm{~cm}$ & $0-320$ & 0.070 & $-0.035(0.005)$ & 0.038 \\
\hline
\end{tabular}

Abbreviation: $\mathrm{DBH}$, diameter at breast height.

The distance range $(\mathrm{m})$ over which SGS was assessed is indicated as is the average kinship coefficient $\left(F_{1}\right)$ between individuals within the first $40 \mathrm{~m}$ distance class. The regression slope of kinship coefficients on a logarithmic scale $(b)$ and the standard error (s.e.) of the slope, derived by jack-knifing over all loci, and SGS intensity $(S p)$ are also presented.
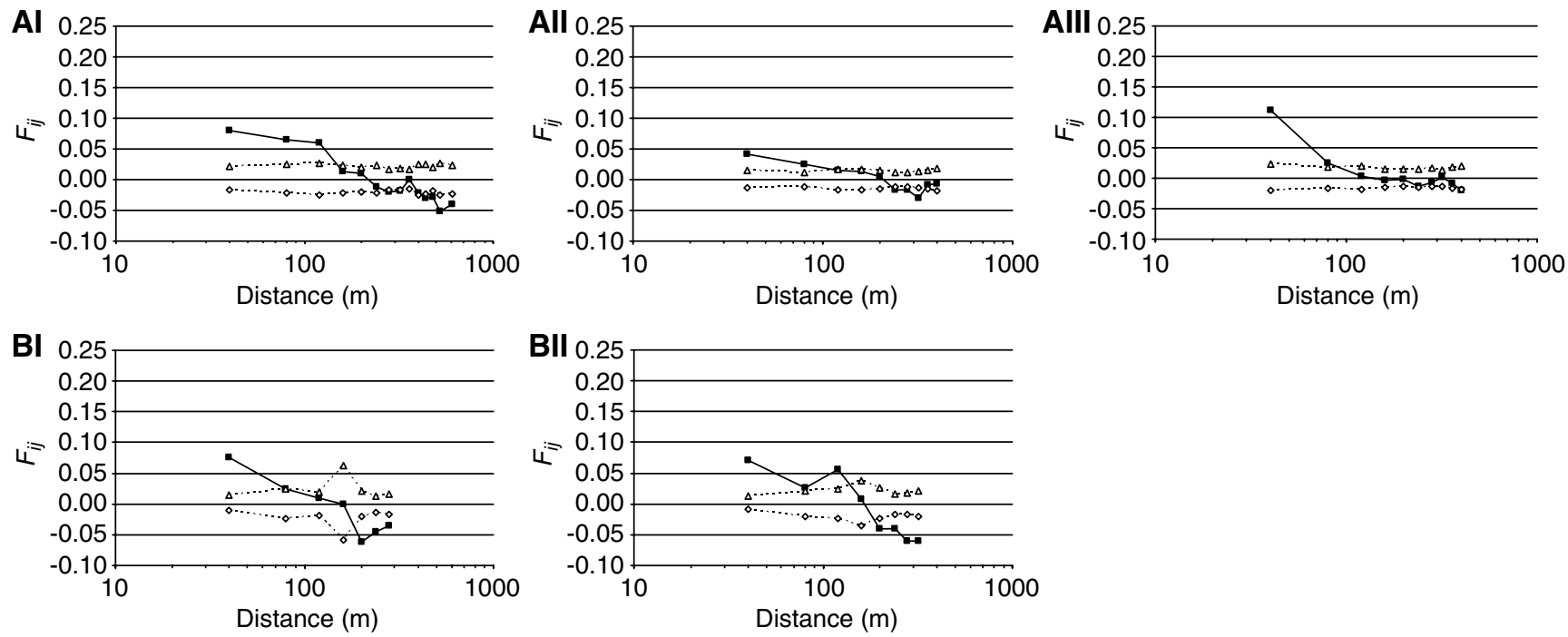

Figure 4 SGS in different size cohorts of sexually reproduced wild cherry under different management regimes. Managed population smallest cohort, $<9.55 \mathrm{~cm}$ DBH (AI); middle cohort, 9.55-19 cm DBH (AII); largest cohort, 19-59 cm DBH (AIII). Unmanaged population: smallest cohort, $<9.55 \mathrm{~cm}$ DBH (BI); middle size and largest sized cohort combined, $9.55-59 \mathrm{~cm} \mathrm{DBH}\left(\right.$ BII). Kinship coefficient $\left(F_{i j}\right)$ values are indicated for $40 \mathrm{~m}$ distance classes with a solid line and a black square. Upper and lower $95 \%$ confidence limits at each size class are indicated by a dotted line with an open triangle and diamond, respectively.

greatly reduced, $S p=0.030$ and $S p=0.045$, for populations $\mathrm{A}$ and $\mathrm{B}$, respectively (Table 2). However, these values still represent high levels of SGS. The decline in kinship with log distance is virtually linear when considering one ramet per genotype in the managed population, indicating that an excess of short-range dispersal events does not bias these data and the $S p$ estimate for this population is fitted over a sufficiently long distance to be reliable.

\section{Impact of size cohort on SGS}

A further factor thought likely to influence SGS in wild cherry was that of size cohort owing to the irregular distribution of $\mathrm{DBH}$ and the link observed between $\mathrm{DBH}$ and floral phenology. To determine if SGS within the sexually derived populations was significantly influenced by tree size, population A (managed) was subdivided into three size cohorts according to $\mathrm{DBH}$,
$<9.55,9.55-19$ and $19-59 \mathrm{~cm}$, with 48,55 and 60 individuals in each cohort, respectively. Because of the smaller size of population B (unmanaged), the two cohorts of largest trees $(9.55-59 \mathrm{~cm})$ were amalgamated to enable analysis, giving 38 individuals in the smallest size cohort and 45 in the larger. In the managed population, SGS declined fairly consistently with distance for all three size cohorts. Significant SGS $\left(F_{i j}\right.$ 0.079-0.061) was observed for the smallest size cohort in the first three distance classes $(40-120 \mathrm{~m})$. Reduced SGS was observed within the middle size cohort ( $F_{i j}$ 0.042-0.025) and only in the 40 and $80 \mathrm{~m}$ distance classes. The highest $F_{i j}$ value for all three size cohorts of the managed population was observed for the first distance class in the largest size cohort $\left(F_{i j}\right.$ 0.112) (Figure 4). The small and large size cohorts also have higher $S p$ values, $S p 0.038$ and $S p$ 0.041, respectively, compared with the middle size cohort, $S p 0.022$ (Table 2). However, the difference between the $S p$ values is only 
Table 3 Estimates of gene dispersal parameters for wild cherry in managed (A) and unmanaged (B) populations. Neighbourhood size $\left(N_{\mathrm{b}}\right)$ and estimated gene dispersal $\left(\sigma_{\mathrm{g}}\right)$ distances $(\mathrm{m})$ with $95 \%$ upper and lower confidence levels in parenthesis are given

\begin{tabular}{lccccc}
\hline Population & $\mathrm{N}_{b}$ & $\sigma_{g}(m)\left(\mathrm{D}_{e}=\mathrm{D} / 2\right)$ & $\sigma_{g}(m)\left(\mathrm{D}_{e}=D / 4.5\right)$ & $\sigma_{g}(m)\left(\mathrm{D}_{e}=\mathrm{D} / 5\right)$ & $\sigma_{g}(m)\left(\mathrm{D}_{e}=\mathrm{D} / 10\right)$ \\
\hline $\mathrm{A}$ & $\mathbf{3 3 . 5}(25.8-47.7)$ & $\mathbf{7 5 . 7}(69.1-94.1)$ & $\mathbf{1 1 6 . 3}(103.7-141.2)$ & $\mathbf{1 2 3 . 5 ( 1 0 9 . 4 - 1 4 8 . 8 )}$ & $\mathbf{1 8 0 . 3}(154.7-210.5)$ \\
$\mathrm{B}$ & $\mathbf{2 2 . 3}(17.2-31.9)$ & $\mathbf{6 3 . 3}(57.3-78.2)$ & $\mathbf{9 3 . 7}(86.0-117.4)$ & $*$ & $*$
\end{tabular}

Only one ramet per genotype was included for the analysis; 163 in population A and 83 in population B resulting in an actual density of adults $(D)$ of 0.0008578 trees per $\mathrm{m}^{2}$ in population $\mathrm{A}$ and 0.0008300 trees per $\mathrm{m}^{2}$ in population B. Gene dispersal was then estimated at four effective densities $\left(D_{\mathrm{e}}\right)$ estimated from the actual density $(D)$. An asterisk indicates that the estimation procedure did not reach convergence at the effective density being tested. $N_{\mathrm{b}}$ values presented are based on the assumed $D_{\mathrm{e}}$ of $D / 2$.

The bold font serves to distinguish the main data presented from the upper and lower confidence levels presented.

marginally significant. In the unmanaged population (B) the decline of SGS with distance was less constant for both size cohorts and the small number of individuals in each cohort resulted in wider confidence margins than were found in the managed population. In the smallest cohort significant $F_{i j}$ values were only observed for the $40 \mathrm{~m}$ distance class $\left(F_{i j}\right.$ 0.075) (Figure 4$)$. However, $F_{i j}$ values were significant in distance classes up to $120 \mathrm{~m}$ for the mid and largest size cohort $\left(F_{i j} 0.070-0.023\right)$, which had to be pooled to enable analysis. The lack of differentiation detected between the cohorts in the unmanaged population is also reflected in the highly similar $S p$ values (Sp 0.042 and $S p$ 0.038) generated for each cohort (Table 2).

\section{Gene dispersal parameters}

Estimated neighbourhood sizes, based on an assumed effective density $\left(D_{\mathrm{e}}\right)$ of $D / 2$ (where $D$ is the density of adult trees), were relatively small at 33.5 and 22.3 in the managed and unmanaged populations, respectively, and a significant degree of overlap occurred within the confidence limits of the two estimates (Table 3). The estimation procedure used to calculate gene dispersal distance $\left(\sigma_{\mathrm{g}}\right)$ did not converge in the unmanaged population for $D_{\mathrm{e}}$ ratios of $D / 5$ and above. However, an upper confidence limit was always obtained, suggesting that the number of loci and polymorphism of alleles was sufficient for the analysis. Gene dispersal distances were somewhat higher in the managed population: $75.7 \mathrm{~m}$ at an effective density of $D / 2$ compared with $63.3 \mathrm{~m}$ in the unmanaged population, but these differences were not statistically significant (Table 3).

\section{Discussion}

Previous studies employing isoenzymes have suggested that little, or at best weak, genetic structuration existed in wild cherry populations (Frascaria et al., 1993; Gömöry and Paule, 2001). However, our data differ strongly and the high $S p$ and $F_{i j}$ values observed in this study suggest that both pollen movement and seed dispersal are indeed limited in this species. Estimates of relatively small neighbourhood size and indirect estimates of gene dispersal distances below $100 \mathrm{~m}$ further support this supposition. With the exception of the most recent twenty years, it is probable that both ancient woodland sites have experienced similar degrees of disturbance over the past several hundred years. However, it is likely that this will mainly have involved removal of mature trees which would have had adequate time in each generation to contribute to development of a stationary SGS representative of the drift-dispersal equilibrium for the site. This assumption is further supported by the linear relationship observed for the regression slope of kinship coefficients when assessing $S p$ values for the two populations combined (data not shown). The majority of loci examined were also found to be at Hardy-Weinberg equilibrium, when only sexually derived individuals were considered, indicating that outbreeding characterizes the two populations. Furthermore, little genetic differentiation was observed between the two populations in terms of $F_{\mathrm{ST}}$ and only somewhat increased segregation was supported in terms of $G_{\mathrm{ST}}$, a statistic which generally provides a higher estimate of differentiation. These findings are in accord with previous studies investigating among population structure in wild cherry (Frascaria et al., 1993; Mariette et al., 1997; Santi, 1988). Alleles found to be exclusive to either population were always at very low frequencies and always in a heterozygous state. This suggests that populations A and $\mathrm{B}$ were established by similar founding material and that subsequent geneflow into the two populations has been similar.

Previous work in P. mahaleb indicated that the majority of seed dispersed beneath a maternal tree were its own progeny with up to $62 \%$ of seeds being delivered within $15 \mathrm{~m}$ of the source tree (Godoy and Jordano, 2001). Earlier studies in wild cherry also noted that the vast majority of wild cherry seed was dispersed no further than $50 \mathrm{~m}$ from the mother tree (Turcek, 1968). Furthermore, Gömöry and Paule (2001) also note that pollen dispersal in wild cherry is poor. Preliminary direct gene-flow estimates from our study site suggest that the majority of pollination events occur between relatively close neighbours. Bumblebees (Bombus spp) are among the major pollinators for wild cherry and the maximum foraging ranges of four UK species have been estimated to range from 449 to $758 \mathrm{~m}$ (Knight et al., 2005). However, resource availability is a key factor influencing foraging and individual bees are likely to visit relatively few mature wild cherries before becoming satiated and returning to the nest, thus limiting pollen dispersal.

It has been demonstrated that high SSR mutation rates can influence the degree to which spatial autocorrelation is observed when the mutation rate is $10^{-2}$ (Epperson, 2005). The polymorphism observed at the 13 loci used in this study is relatively consistent across all loci and can be described as moderate, which confers confidence in the subsequent SGS analysis. For example, in Fagus crenata, three SSR loci were evaluated and an average of 24.3 alleles per locus was observed (Asuka et al., 2004). In a Europe-wide study of Fraxinus excelsior, an average of 54.6 alleles was observed over the five loci examined (Heuertz et al., 2004). These data represent 
polymorphism between two and four times that observed at the SSR loci used in this study. Thus, it can be argued that the loci employed in this study are not highly mutable. During the course of this study, it was also shown that the SSR markers employed may have potential for population studies in further Prunus species. Distinct SSR profiles were observed for trees of $P$. cerasus, planted nearby, and for three ornamental Prunus species ( $P$. subhirtella, $P$. sargentii, $P$. serrulata) present in a garden adjacent to population B.

Management regime and tree age have both been shown to influence SGS in a number of forest tree species. In Sorbus torminalis, genetic structure was highest and significant within the two shortest distance classes $(<400 \mathrm{~m})$ and found to be associated with logging cycles and sibling cohorts colonizing favourable sites (Oddou-Muratorio et al., 2004). The $S p$ values for $S$. torminalis (Vekemans and Hardy, 2004) were approximately half of those observed for wild cherry in this study. This may result from the lower density of the Sorbus population examined $(<0.4$ trees $/ \mathrm{Ha})$ compared with the wild cherry in this study ( $\sim 16.5$ to $\sim 23.7$ trees/ $\mathrm{Ha}$ ). In F. crenata, stronger spatial structure was observed in short distance classes $(10 \mathrm{~m})$ and, as with the managed wild cherry, greater structure was observed within the younger cohort of trees (Asuka et al., 2004).

Distribution of individuals within a population is another factor that may influence the degree to which SGS arises. In the case of F. crenata, individuals occurred at a density of $\sim 200$ trees/Ha; the authors felt that this may have been a significant factor in reducing the genetic structuration observed, as seed shadows from individual trees would overlap at these densities (Asuka et al., 2004). In our study sites, wild cherry occurs in loosely clustered groups at densities where pollen and seed dispersal are likely to occur between near neighbours and yet individual seed shadows are far less likely to overlap than those of more densely distributed species.

In P. mahaleb, it was shown that variation in local tree density affected pollen pool diversity, with trees in low density patches receiving pollen from a higher number of fathers over longer intermediate distances than trees in high-density patches (Garcia et al., 2005). In the unmanaged wild cherry population, both sexual and asexual regeneration levels were high and there was a marked increase in the proportion of trees in the smallest DBH class. It is likely that storm felled trees remaining in situ over the past 20 years has promoted increased aggregation of both seedlings and suckers in this cohort owing to increased light availability and root disturbance. As a result, wild cherry occurs in relatively high-density patches in this population, which may contribute to the high degree of SGS seen in the smaller distance classes. Localized SGS may also be further reinforced by clonal genotypes dominating seed production at the local scale in this population.

The $S p$ values observed in this study, reflecting significant levels of SGS for both populations, are among the highest observed in tree species (see Table 1; Vekemans and Hardy, 2004) and similar to those observed for Vouacapoua americana, which is a tropical hardwood, also characterized as an outcrosser (Dutech et al., 2002). Our findings may have been influenced by the exhaustive sampling strategy we adopted, as well as the ecology of the species. The relatively small scale of the study site, below $20 \sigma$ of gene dispersal estimates, may also have influenced the calculation of Sp. SGS should ideally be evaluated in a distance range between $\sigma$ and about $20 \sigma$ of gene dispersal (Heuertz et al., 2003). In Common Ash, Heuertz et al. (2003) demonstrated that at shorter distances the relative contributions of pollen and seed dispersal greatly influence the curvature of $F_{i j}$ values plotted against distance, with narrow dispersal of seed resulting in an upward concave initial curving. Restricted genotype dispersal brought about through clonal reproduction in cherry appeared to result in a similar concave curvature of $F_{i j}$ values. However, the linear kinship-distance plots we obtained when evaluating one ramet per genet suggest that an adequate scale was examined to assess SGS reliably.

Previously, Gömöry and Paule (2001) reported limited SGS, based on data from seven isoenzyme loci, in Slovakian wild cherry for distances up to $36.8 \mathrm{~m}$. However, the spatial distribution of individuals in the Slovakian population was atypical, with wild cherry forming almost parallel rows over recently colonized rocky baulks. Our examination of managed climax woodland revealed significant SGS within the youngest cohort up to $120 \mathrm{~m}$ and, contrary to our original hypothesis, high SGS within the $40 \mathrm{~m}$ distance class for the largest cohort. It is likely that the SGS observed in the youngest cohort arises from limited seed dispersal from mother trees and is subsequently reduced as natural selection and random mortality causes a gradual reduction in genetic structuration as the cohort matures. Similar findings were observed for the seedling cohort of Simarouba amara, an animal dispersed Neotropical tree species (Hardesty et al., 2005). However, the structuration we observed within the oldest cherry cohort in the managed population is contrary to the concept of demographic thinning reducing SGS. There is a strong genetic component determining the characters that produce a desirable timber tree (Muranty et al., 1998), and it is possible that removal of undesirable phenotypes may have homogenized the genetic component of trees in favour of family groups sharing desirable traits (as well as inherited neutral markers), thus increasing SGS in smaller distance classes for the mature cohort.

A further factor which may reinforce the differential levels of SGS observed between size cohorts is that of floral phenology. The majority of trees in the smallest DBH size class attained over $50 \%$ full bloom significantly earlier than those in older cohorts. Early flowering in wild cherry is often disadvantageous, with late frosts destroying open flowers and preventing fruit from forming (S Vaughan and $\mathrm{K}$ Russell, unpublished data). Over $99 \%$ of the trees identified in the study site produced flowers in the year of study. However, decreased flower numbers, discrete floral timing and frost damage are all likely to limit the contribution of the younger cohort to reproductive processes in the population as a whole. This consideration is also of importance when estimating effective densities and gene dispersal distances. Between 20 and $25 \%$ of sexually derived individuals were below $9.55 \mathrm{~cm} \mathrm{DBH}$ and thus less likely to make a significant contribution to the overall gene flow. Therefore, an effective density of $D / 4$, as previously suggested by Hardy et al. (2006), may be more realistic to describe those individuals regularly 
producing large amounts of pollen and seeds and contributing to successive generations. If the majority of genetic interaction does indeed occur between mature individuals, this would also strengthen kinship relationships between successive germination years and account for the strong SGS observed in the youngest cohorts.

To date, relatively little is known regarding pollen and seed dispersal in wild cherry. However, an improved understanding of SGS and the processes influencing the non-random dispersal of genotypes will enable the development of informed conservation and breeding strategies for this species. In light of the kinship groupings observed in this case study, we would recommend only selective removal of mature trees for timber to prevent complete elimination of family groups. The high degree of asexual recruitment and SGS observed also suggests that individuals, particularly in unmanaged populations, are likely to be closely related to or of the same clone as their nearest neighbours. Thus, we also recommend that minimum distances of at least $100 \mathrm{~m}$ should be imposed between trees selected for seed stands to promote genotypic diversity in any progeny raised. Furthermore, additional studies utilizing microsatellite data are now required to verify that the high degree of SGS observed in this study is typical of the species in general.

\section{Acknowledgements}

We express our gratitude to the Woodland Trust for allowing access to the study site, to Mr JC Tattershall for assistance in the field and to $\mathrm{Mr}$ Andrew Peace for statistical assistance. We also thank Mr Kenneth Tobutt, Dr Myriam Heuertz and two anonymous reviewers for many helpful suggestions on a previous draft of the manuscript. This work was supported by funding from the Defra and the Forestry Commission (under Grant WD0502).

\section{References}

Asuka Y, Tomaru N, Nisimura N, Tsumura Y, Yamamuto S (2004). Heterogeneous genetic structure in a Fagus crenata population in an old growth beech forest revealed by microsatellite markers. Mol Ecol 13: 1241-1250.

Chung MG, Epperson BK (2000). Clonal and spatial genetic structure in Eurya emarginata (Theaceae). Heredity 84: 170-177.

Cipriani G, Lot G, Huang WG, Marrazzo MT, Peterlunger E, Testolin R (1999). AC/GT and AG/CT microsatellite repeats in peach Prunus persica (L.) Batsch: isolation, characterisation and cross-species amplification in Prunus. Theor Appl Genet 99: 65-72.

Clark PJ, Evans FC (1954). Distance to nearest neighbour as a measure of spatial relationships in populations. Ecology 35 445-453.

Cottrell JE, Munro RC, Tabbenner HE, Milner AD, Forrest GI, Lowe AJ (2003). Comparison of fine-scale genetic structure using microsatellites within two British oakwoods differing in population history. For Ecol Manage 176: 287-303.

Degen B, Petit R, Kremer A (2001). SGS-Spatial Genetic Software: a computer program for analysis of spatial genetic and phenotypic structures of individuals and populations. J Heredity 92: 447-448.

Dutech C, Seitier J, Petronelli P, Joly HI, Jarne P (2002). Evidence of low gene flow in a neotropical clustered tree species in two rainforest stands of French Guiana. Mol Ecol 11: 725-738.
Downey SL, Iezzoni AF (2000). Polymorphic DNA markers in black cherry (Prunus serotina) are identified using sequences from sweet cherry, peach and sour cherry. J Am Soc Hortic Sci 125: 76-80.

Epperson BK (2005). Mutation at high rates reduces spatial structure within populations. Mol Ecol 14: 703-710.

Frascaria N, Santi F, Gouyon PH (1993). Genetic differentiation within and among populations of chestnut (Castanea sativa Mill) and wild cherry (Prunus avium L). Heredity 70: 634-641.

Garcia C, Arroyo JM, Godoy JA, Jordano P (2005). Mating patterns, pollen dispersal, and the ecological maternal eighbourhood in a Prunus mahaleb L. population. Mol Ecol 14: 1821-1830.

Godoy JA, Jordano P (2001). Seed dispersal by animals: exact identification of source trees with endocarp DNA microsatellites. Mol Ecol 10: 2275-2283.

Gömöry D, Paule L (2001). Spatial structure and mating system in wild cherry (Prunus avium) population. Biol Bratislava 56: 117-123.

Goudet J (1995). FSTAT (version 1.2): a computer program to calculate F-statistics. J Heredity 86: 485-486.

Hardesty BD, Dick CW, Kremer A, Hubbell A, Bermingham E (2005). Spatial genetic structure of Simarouba amara Aubl. (Simaroubaceae), a dioecious, animal-dispersed Neotropical tree, on Barro Colorado Island, Panama. Heredity 95: 290-297.

Hardy OJ, Maggia L, Bandou E, Breyne P, Caron H, Chevallier $\mathrm{M}-\mathrm{H}$ et al. (2006). Fine-scale genetic structure and gene dispersal inferences in 10 Neotropical tree species. Mol Ecol 15: 559-571.

Hardy OJ, Vekemans X (2002). SPAGeDI: a versatile computer program to analyse spatial genetic structure at the individual or population levels. Mol Ecol Primer Notes 2: 618.

Hedrick PW (2005). A standardized genetic differentiation measure. Evolution 59: 1633-1638.

Heuertz M, Hausman J-F, Hardy OJ, Vendramin GG, FrascariaLacoste N, Vekemans X (2004). Nuclear microsatellites reveal contrasting patterns of genetic structure between western and South-Eastern European populations of the common ash (Fraxinus excelsior L.). Evolution 58: 976-988.

Heuertz M, Vekemans X, Hausman J-F, Palada M, Hardy OJ (2003). Estimating seed vs. pollen dispersal from spatial genetic structure in the common ash. Mol Ecol 12: 2483-2495.

Knight ME, Martin AP, Bishop S, Osbourne JL, Hale RJ, Sanderson RA et al. (2005). An interspecific comparison of foraging range and nest density of four bumblebee (Bombus) species. Mol Ecol 14: 1811-1820.

Loiselle BA, Sork Vl, nason J, Graham C (1995). Spatial genetic structure of tropical understory shrub, Psychotria officinalis (Rubiaceae). Am J Bot 82: 1420-1425.

Mariette S, Lefranc M, Legrand P, Taneyhill D, Frascaria-Lacoste N, Machon N (1997). Genetic variability in wild cherry populations in France. Effects of colonizing processes. Theor Appl Genet 94: 904-908.

Marquardt PE, Epperson BK (2004). Spatial and population genetic structure of microsatellites in white pine. Mol Ecol 13: 3305-3315.

Marshall T, Slate J, Kruuk L, Pemberton J (1998). Statistical confidence for likelihood-based paternity inference in natural populations. Mol Ecol 7: 639-655.

Muranty H, Schermann N, Santi F, Dufour J (1998). Genetic parameters estimated from a wild cherry diallel: consequences for breeding. Silvae Genet 47: 249-257.

Nei M (1987). Molecular Evolutionary Genetics. Columbia University Press: New York.

Oddou-Muratorio S, Demesure B, Pelissier R, Gouyon PH (2004). Impacts of gene flow and logging history on the local genetic structure of a scattered tree species, Sorbus torminalis L.Crantz. Mol Ecol 13: 3689-3702.

Russell K (2003). EUFORGEN Technical guidelines for genetic conservation and use for wild cherry (Prunus 
avium). International Plant Genetics Resources Institute, Rome, Italy, $6 \mathrm{p}$.

Santi F (1988). Variabilité génétique intra et inter-populationns chez le merisier (Prunus avium L.). Thesis of the Institut National Agronomique Paris Grignon, 80p.

Siegel S (1956). Nonparametric Statistics for the Behavioural Sciences. McGraw-Hill: New York.

Schneider S, Kueffer J-M, Roessli D, Escoffier L (1997). Arlequin, Version 1.1: a software program for population genetic data analysis, Genetics and Biometry Laboratory, University of Geneva, Switzerland.

Silvertown J (2001). Plants stand still but their genes don't: non-trivial consequences of the obvious. In: Silvertown J, Antonovics J (eds), Integrating Evolution and Ecology in a Spatial Context. Cambridge University Press: Cambridge. p 347.

Streiff R, Labbe T, Bacilieri R, Steinkellner H, Glassl J, Kremer A (1998). Within-population genetic structure in Quercus robur
L. and Quercus petraea (Matt.) Liebl. assessed with isozymes and microsatellites. Mol Ecol 7: 317-328.

Turcek FJ (1968). The dissemination of Prunus avium L. by birds in forests. Waldhygiene 7: 129-132.

Vaughan SP, Russell K (2004). Characterization of novel microsatellites and development of multiplex PCR for large-scale population studies in wild cherry, Prunus avium. Mol Ecol Primer Notes 4: 429-431.

Vekemans X, Hardy OJ (2004). New insights from fine-scale spatial genetic structure analyses in plant populations. Mol Ecol 13: 921-935.

Ward M, Dick CW, Gribel R, Lemes M, Caron H, Lowe AJ (2005). To self, or not to self. A review of outcrossing and pollen-mediated gene flow in neotropical trees. Heredity 95 : 246-254.

Weir BS, Cockerham CC (1984). Estimating F-statistics for the analysis of population structure. Evolution 38: 1358-1370.

Supplementary Information accompanies the paper on Heredity website (http://www.nature.com/hdy) 